\title{
Long-Term Management of Venous Thromboembolism: Lessons from EINSTEIN CHOICE and Other Extension Trials
}

\author{
Jeffrey I. Weitz ${ }^{1}$ Noel C. Chan ${ }^{1}$ \\ ${ }^{1}$ Thrombosis and Atherosclerosis Research Institute, McMaster \\ University, Hamilton, Ontario, Canada
}

Thromb Haemost 2019;119:689-694.
Address for correspondence Jeffrey I. Weitz, MD, Thrombosis and Atherosclerosis Research Institute, 237 Barton Street East, Hamilton, Ontario L8L 2X2, Canada (e-mail: weitzj@mcmaster.ca).

\begin{abstract}
Keywords

- venous thromboembolism

- anticoagulation

- extended therapy

- rivaroxaban

- acetylsalicylic acid

Many patients with venous thromboembolism (VTE) are at risk of recurrence if anticoagulant therapy is stopped. Whereas 3 months of anticoagulation treatment is sufficient for patients with VTE provoked by major surgery or trauma, in many cases a longer course is needed. Extended therapy with vitamin $\mathrm{K}$ antagonists (VKAs) requires frequent coagulation monitoring and dose adjustments to ensure that the international normalized ratio (INR) remains within the therapeutic range; furthermore, there is a risk of major bleeding even if a therapeutic INR is maintained. Therefore, more convenient and safer anticoagulants are needed.

The non-VKA oral anticoagulants (NOACs)-apixaban, dabigatran, edoxaban and rivaroxaban-simplify extended therapy because they can be given in fixed doses without routine coagulation monitoring. Randomized clinical trials have demonstrated the efficacy and safety of NOACs for extended VTE treatment, but bleeding remains a concern. Patients and physicians may, therefore, be reluctant to continue anticoagulation beyond 3 to 6 months except in patients at high risk of recurrence. Acetylsalicylic acid (ASA) is often prescribed instead of an anticoagulant because of its perceived lower risk of bleeding; however, the recent EINSTEIN CHOICE trial demonstrated that once-daily rivaroxaban at a dose of either 20 or $10 \mathrm{mg}$ reduced the risk of recurrent VTE by $70 \%$ compared with ASA without significantly increasing the risk of bleeding. In this review, we discuss the EINSTEIN CHOICE trial in the context of previous trials for extended VTE treatment and examine some of the lessons that can be applied to clinical practice.
\end{abstract}

\section{Introduction}

Most patients with venous thromboembolism (VTE), which includes deep vein thrombosis and pulmonary embolism, are treated with anticoagulant therapy for at least 3 months. Continuing anticoagulant therapy depends on the balance between the patient's risk of VTE recurrence if treatment is stopped and the risk of bleeding with continued treatment. Patient preference also needs to be considered. ${ }^{1}$

Although a 3-month course of anticoagulation therapy is sufficient for patients with VTE provoked by major transient risk factors such as surgery or trauma, those with unpro-

voked VTE or VTE related to active cancer are recommended to receive a longer course of therapy unless their risk of bleeding is high. ${ }^{1}$ Traditionally, VTE is considered unprovoked if it occurs in the absence of major risk factors such as recent surgery or trauma, active cancer, pregnancy or oestrogen use. ${ }^{2}$ However, in recent years several additional risk factors have been identified, including long-distance travel, ${ }^{3}$ lower limb paresis or paralysis, ${ }^{4}$ obesity, ${ }^{5}$ inflammatory bowel disease ${ }^{6,7}$ and renal impairment. ${ }^{8}$ Therefore, it is now recommended that provoked VTE be further classified depending on whether risk factors are major or minor and persistent or transient. ${ }^{2}$

(c) 2019 Georg Thieme Verlag KG Stuttgart · New York
DOI https://doi.org/ $10.1055 / \mathrm{s}-0039-1679906$. ISSN 0340-6245.
September 21, 2018

accepted after revision January 10, 2019 
Extended anticoagulation with vitamin $\mathrm{K}$ antagonists (VKAs), such as warfarin, is problematic. Although such therapy reduces the risk of recurrent VTE, it is associated with a nearly threefold increase in the risk of major bleeding. ${ }^{9}$ Furthermore, VKAs are cumbersome to administer because they require frequent coagulation monitoring and dose adjustments to ensure that the international normalized ratio (INR) remains within the therapeutic range of 2.0 to 3.0. ${ }^{1}$ Such monitoring is inconvenient for patients and physicians and places considerable burden on health care resources. Consequently, many patients with VTE elect to stop treatment with VKAs. Acetylsalicylic acid (ASA) is suggested in such patients ${ }^{1}$ because, compared with placebo, it was shown to reduce the risk of recurrent VTE by $32 \%$ without significantly increasing the risk of major or clinically relevant non-major (CRNM) bleeding. ${ }^{10}$

The non-VKA oral anticoagulants (NOACs) were introduced to overcome many of the limitations of VKAs. Unlike VKAs, the NOACs can be administered in fixed doses without routine coagulation monitoring. Compared with VKAs for the treatment of VTE, the NOACs had similar efficacy and were associated with an approximately $40 \%$ reduction in major bleeding. ${ }^{11}$ In this review, we will discuss the evidence base for the use of the NOACs for extended treatment of VTE, focusing on the recent EINSTEIN CHOICE trial, which compared two doses of rivaroxaban with ASA for extended VTE treatment. ${ }^{12}$

\section{Extended Anticoagulation: The Role of Non- Vitamin K Antagonist Oral Anticoagulants}

To date, randomized clinical trials have investigated the efficacy and safety of extended anticoagulation with three NOACs (i.e. rivaroxaban, dabigatran and apixaban) in patients who had already received a period of anticoagulant therapy after a confirmed VTE. ${ }^{13-15}$ The results of these studies are summarized in - Table 1.

In the EINSTEIN EXT study, extended treatment with rivaroxaban $20 \mathrm{mg}$ once daily was compared with placebo in patients who had completed 6 to 12 months of prior anticoagulation therapy and were in clinical equipoise regarding the need for continued therapy. ${ }^{13}$ Rivaroxaban was associated with a significant $82 \%$ reduction in the risk of recurrent VTE (from 7.1 to $3.2 \%$ ) versus placebo, with no significant increase in the primary safety outcome of major bleeding (although a significant increase in major or CRNM bleeding was reported). Two extension studies investigated the efficacy and safety of dabigatran $150 \mathrm{mg}$ twice daily for the prevention of recurrent VTE in patients who had completed at least 3 months of anticoagulation therapy for their index event. ${ }^{15}$ In the active-controlled RE-MEDY study, dabigatran was non-inferior to warfarin for efficacy and was associated with a non-significantly lower rate of major bleeding and a significantly lower rate of major or CRNM bleeding, compared with warfarin. ${ }^{15}$ In the placebo-controlled RE-SONATE study, dabigatran was superior to placebo for efficacy but was associated with a significant increase in major or CRNM bleeding. ${ }^{15}$ The AMPLIFY-EXT study compared the treatment dose of apixaban ( $5 \mathrm{mg}$ twice daily) and the dose used for thromboprophylaxis ( $2.5 \mathrm{mg}$ twice daily) with placebo for extended treatment in patients with VTE who had completed 6 to 12 months of prior anticoagulation therapy and were in clinical equipoise regarding the need for continued therapy. Compared with placebo, both doses of apixaban were associated with significant reductions in the primary outcome of recurrent VTE or all-cause mortality, as well as in recurrent VTE or VTE-related death. ${ }^{14}$ Neither dose of apixaban was associated with a significant increase in major bleeding or major or CRNM bleeding compared with

Table 1 Summary of randomized controlled trials for extended treatment of VTE with NOACs

\begin{tabular}{|c|c|c|c|c|c|}
\hline Trial name & Study drug & Comparator & $\begin{array}{l}\text { Duration of } \\
\text { previous } \\
\text { anticoagulation }\end{array}$ & $\begin{array}{l}\text { Primary efficacy endpoint } \\
\text { (study drug vs. comparator) }\end{array}$ & $\begin{array}{l}\text { Primary safety endpoint } \\
\text { (study drug vs. comparator) }\end{array}$ \\
\hline $\begin{array}{l}\text { EINSTEIN } \\
\text { EXT }^{13}\end{array}$ & $\begin{array}{l}\text { Rivaroxaban } \\
20 \mathrm{mg} \text { od }\end{array}$ & Placebo & $6-12$ months & $\begin{array}{l}\text { Recurrent VTE: } 1.3 \% \text { vs. } 7.1 \% \text {, } \\
p<0.001\end{array}$ & $\begin{array}{l}\text { Major bleeding: } 0.7 \% \text { vs. } 0 \% \text {, } \\
p=0.11\end{array}$ \\
\hline RE-MEDY ${ }^{15}$ & $\begin{array}{l}\text { Dabigatran } \\
150 \text { mg bid }\end{array}$ & Warfarin & $\geq 3$ months & $\begin{array}{l}\text { Recurrent or fatal VTE: } 1.8 \% \text { vs. } \\
1.3 \%, p=0.01 \text { for non- } \\
\text { inferiority }\end{array}$ & $\begin{array}{l}\text { Major bleeding: } 0.9 \% \text { vs. } 1.8 \% \text {, } \\
p=0.06\end{array}$ \\
\hline RE-SONATE ${ }^{15}$ & $\begin{array}{l}\text { Dabigatran } \\
150 \mathrm{mg} \text { bid }\end{array}$ & Placebo & $\geq 3$ months & $\begin{array}{l}\text { Recurrent or fatal VTE: } 0.4 \% \text { vs. } \\
5.6 \%, p<0.001\end{array}$ & $\begin{array}{l}\text { Major bleeding: } 0.3 \% \text { vs. } 0 \% \text {, } \\
p=1.0\end{array}$ \\
\hline \multirow[t]{2}{*}{ AMPLIFY-EXT ${ }^{14}$} & $\begin{array}{l}\text { Apixaban } \\
2.5 \mathrm{mg} \text { bid }\end{array}$ & \multirow[t]{2}{*}{ Placebo } & \multirow[t]{2}{*}{$6-12$ months } & $\begin{array}{l}\text { Recurrent VTE or all-cause } \\
\text { mortality: } 3.8 \% \text { vs. } 11.6 \% \text {, } \\
p<0.001\end{array}$ & $\begin{array}{l}\text { Major bleeding: } 0.2 \% \text { vs. } 0.5 \% \\
\text { (p-value not reported) }\end{array}$ \\
\hline & $\begin{array}{l}\text { Apixaban } \\
5 \mathrm{mg} \text { bid }\end{array}$ & & & $\begin{array}{l}\text { Recurrent VTE or all-cause } \\
\text { mortality: } 4.2 \% \text { vs. } 11.6 \% \text {, } \\
p<0.001\end{array}$ & $\begin{array}{l}\text { Major bleeding: } 0.1 \% \text { vs. } 0.5 \% \\
\text { (p-value not reported) }\end{array}$ \\
\hline \multirow[t]{2}{*}{$\begin{array}{l}\text { EINSTEIN } \\
\text { CHOICE }^{12}\end{array}$} & $\begin{array}{l}\text { Rivaroxaban } \\
10 \mathrm{mg} \text { od }\end{array}$ & ASA & $6-12$ months & $\begin{array}{l}\text { Recurrent or fatal VTE: } \\
1.2 \% \text { vs. } 4.4 \%, p<0.001\end{array}$ & $\begin{array}{l}\text { Major bleeding: } \\
0.4 \% \text { vs. } 0.3 \%, p=0.32\end{array}$ \\
\hline & $\begin{array}{l}\text { Rivaroxaban } \\
20 \text { mg od }\end{array}$ & ASA & $6-12$ months & $\begin{array}{l}\text { Recurrent or fatal VTE: } \\
1.5 \% \text { vs. } 4.4 \% p<0.001\end{array}$ & $\begin{array}{l}\text { Major bleeding: } \\
0.5 \% \text { vs. } 0.3 \%, p=0.50\end{array}$ \\
\hline
\end{tabular}

Abbreviations: ASA, acetylsalicylic acid; bid, twice daily; NOAC, non-vitamin K antagonist oral anticoagulant; od, once daily; VTE, venous thromboembolism. 
placebo. A fourth NOAC, edoxaban, has not been evaluated in a dedicated extension study; however, in the Hokusai-VTE trial, patients received between 3 and 12 months of anticoagulation with edoxaban $60 \mathrm{mg}$ once daily (edoxaban $30 \mathrm{mg}$ once daily in patients with reduced renal function or low body weight) or warfarin after a confirmed venous thromboembolic event. ${ }^{16}$ A sub-analysis of this study showed that when therapy was extended beyond 3 months after the index event, edoxaban was as effective as warfarin and was associated with a similar risk of clinically relevant bleeding but a lower risk of major bleeding. ${ }^{17}$

Compared with VKAs, the NOACs have several advantages for patients and physicians. Thus, the NOACs are not influenced by dietary vitamin $\mathrm{K}$ intake, have few drug-drug interactions and can be given in fixed doses without the need for routine coagulation monitoring. Reflecting these reduced burdens in conjunction with the efficacy and safety profiles demonstrated in the extension studies, the most recent guidelines from the American College of Chest Physicians recommend NOAC therapy in preference to VKAs for VTE treatment in patients without active cancer. ${ }^{1}$ In patients with active cancer, guidelines continue to endorse lowmolecular-weight heparin (LMWH) as the standard of care because LMWH has shown superior long-term efficacy compared with VKAs in patients with cancer-associated thrombosis. ${ }^{18}$ Compared with LMWH, NOACs have the advantage of being less expensive and avoiding the need for daily injections, but until the recent publications of the Hokusai-VTECancer and select-d studies, ${ }^{19,20}$ no clinical trial had directly compared their efficacy and safety. The favourable results with edoxaban and rivaroxaban in cancer-associated thrombosis have prompted changes to guidelines. ${ }^{21}$ Current guidance now suggests the use of edoxaban or rivaroxaban for cancer patients with an acute diagnosis of VTE, a low risk of bleeding and no relevant drug-drug interactions. LMWH is an acceptable alternative for such patients and remains the agent of choice for cancer patients at high risk of bleeding, such as those with luminal gastrointestinal cancers with an intact primary, cancers of the genitourinary tract at risk of bleeding, patients with nephrostomy tubes or those with gastrointestinal mucosal abnormalities such as esophagitis, gastritis, peptic ulcer disease or colitis.

Despite the greater convenience and similar or improved safety of NOACs compared with VKAs, many patients elect to stop anticoagulation because of the cost of NOACs or a fear of bleeding. In these cases, guidelines suggest the use of ASA therapy in preference to no therapy at all. ${ }^{1}$ This guidance is based on the outcomes of the WARFASA and ASPIRE trials, ${ }^{22,23}$ both of which investigated the efficacy and safety of ASA compared with placebo for extended secondary prevention in patients with unprovoked VTE who had completed at least a 3-month course of anticoagulation with a VKA. In a pooled analysis of these two studies (the INSPIRE collaboration), the use of ASA $100 \mathrm{mg}$ once daily reduced the risk of recurrent VTE by $32 \%$ compared with placebo over a median follow-up of 30.4 months with no significant increase in major or CRNM bleeding. ${ }^{10}$ This risk reduction is substantially smaller than for anticoagulation, which is expected to reduce recurrent VTE rates by more than $80 \%{ }^{24,25}$ therefore, ASA is only recommended for patients at risk of recurrent VTE who have declined to continue anticoagulation therapy. ${ }^{1}$

\section{Finding the Optimal Benefit-Risk Profile for Extended Anticoagulation Therapy: Reduced versus Full-Dose Rivaroxaban or Apixaban}

In light of the above guideline recommendation, and building on previous successful extension studies, the recent EINSTEIN CHOICE study investigated the efficacy and safety of two once daily doses of rivaroxaban versus ASA for extended VTE treatment. ${ }^{12}$ Patients who had already received 6 to 12 months of anticoagulation therapy and were in equipoise regarding the need for continued anticoagulation treatment were randomized $1: 1: 1$ to receive up to 12 months of therapy with rivaroxaban $20 \mathrm{mg}$ once daily, rivaroxaban $10 \mathrm{mg}$ once daily or ASA $100 \mathrm{mg}$ once daily. A total of 3,396 patients underwent randomization, most of whom (59\%) had provoked VTE. The patients included had an index event of confirmed symptomatic proximal deep vein thrombosis (51\%), pulmonary embolism (34\%) or both (15\%).

Both rivaroxaban $20 \mathrm{mg}$ once daily and rivaroxaban $10 \mathrm{mg}$ once daily were associated with significant reductions in VTE recurrence versus ASA (rates of recurrence were $4.4 \%$ with ASA, $1.5 \%$ with rivaroxaban $20 \mathrm{mg}$ once daily and $1.2 \%$ with rivaroxaban $10 \mathrm{mg}$ once daily, equating to a $66 \%$ relative risk reduction with the rivaroxaban $20 \mathrm{mg}$ dose and a 74\% relative risk reduction with the rivaroxaban $10 \mathrm{mg}$ dose; $p<0.001$ for both comparisons) ( - Fig. 1A). Safety outcomes were similar between the three arms, with no significant increase in the incidence of major or CRNM bleeding with either dose of rivaroxaban (rates of major bleeding were $0.3 \%$ with ASA, $0.5 \%$ with rivaroxaban $20 \mathrm{mg}$ once daily and $0.4 \%$ with rivaroxaban $10 \mathrm{mg}$ once daily) (- Fig. 1B). The relative risk reductions for VTE recurrence were similar in patients with a provoked or unprovoked index event, although the rate of recurrence was higher in patients with unprovoked VTE in all three study arms. ${ }^{12}$

These results were broadly consistent with those of the earlier AMPLIFY-EXT trial, which compared apixaban at doses of $5 \mathrm{mg}$ twice daily or $2.5 \mathrm{mg}$ twice daily with placebo. ${ }^{14}$ In both trials, both doses of the NOACs were associated with a significant reduction in recurrent VTE (vs. placebo in the case of AMPLIFY-EXT and ASA in the case of EINSTEIN CHOICE), with a trend towards lower rates of major or CRNM bleeding in patients receiving the lower dose.

The benefit-risk profile of reduced doses of rivaroxaban or apixaban was examined in a recent meta-analysis that included both trials. ${ }^{26}$ Compared with full-dose apixaban or rivaroxaban, the reduced dose regimens were associated with a trend for lower rates of clinically relevant bleeding (2.3\% vs. 3.7\%; risk ratio [RR] $0.74 ; 95 \%$ confidence interval [CI], 0.52-1.05) and no significant increase in recurrent VTE (1.6\% vs. $1.4 \%$; RR, 1.12 ; 95\% CI, $0.67-1.87) .{ }^{26}$ Consequently, these results suggest that reduced doses of either rivaroxaban or apixaban provide greater safety than full doses 


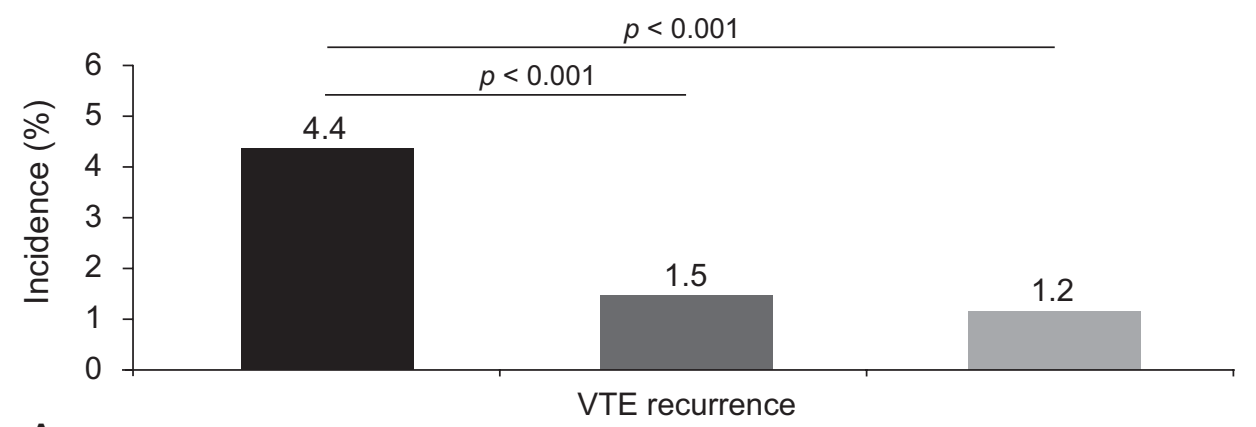

A

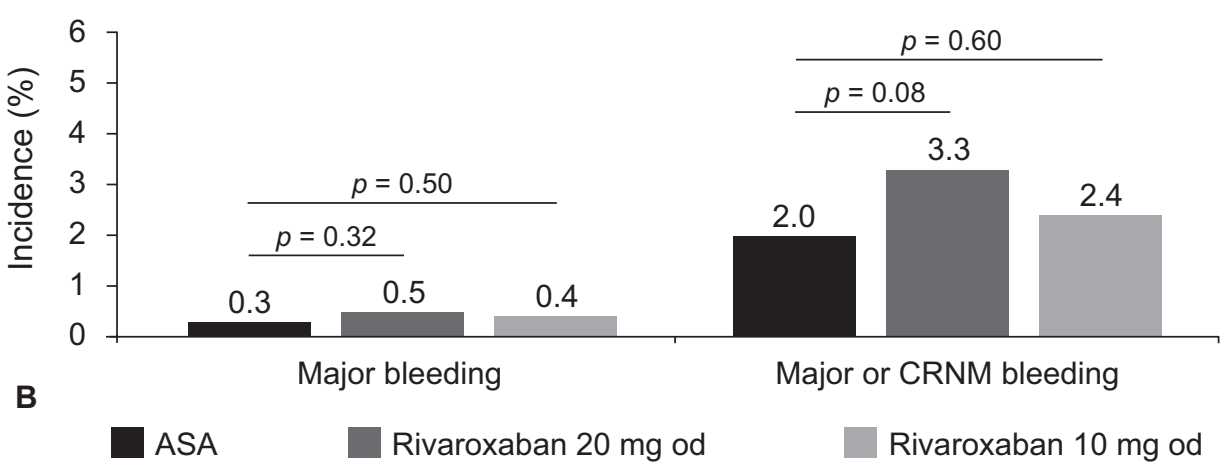

Fig. 1 Key efficacy (A) and safety (B) outcomes in EINSTEIN CHOICE. ASA, acetylsalicylic acid; CRNM, clinically relevant non-major; od, once daily; VTE, venous thromboembolism.

without loss of efficacy. Future post-marketing studies are required to confirm these favourable results.

\section{What Have We Learnt from EINSTEIN CHOICE?}

The EINSTEIN CHOICE results provided three key lessons for the future treatment and secondary prevention of VTE. First, rivaroxaban was more effective than ASA without incurring a significant increase in the risk of bleeding. Second, although both doses were more effective than ASA, rivaroxaban $10 \mathrm{mg}$ once daily was associated with a trend for a lower rate of bleeding compared with rivaroxaban $20 \mathrm{mg}$ once daily, suggesting an improved benefit-risk profile. For every 10,000 patients treated for 1 year with rivaroxaban instead of ASA, there would be 284 (95\% CI, 106-463) fewer episodes of symptomatic VTE or major bleeding with the rivaroxaban $20 \mathrm{mg}$ dose and 339 (95\% CI, 165-512) fewer events with the rivaroxaban $10 \mathrm{mg}$ dose. ${ }^{27}$

This was not the case with low-intensity warfarin: in the ELATE trial, the rate of recurrent VTE was 2.8-fold higher with low-intensity warfarin (target INR $1.5-1.9$ ) than with usual-intensity warfarin (target INR 2.0-3.0) without a reduction in overall bleeding. ${ }^{28}$ Finally, rivaroxaban significantly reduced the risk of recurrence in patients with provoked VTE, as well as unprovoked VTE. ${ }^{12}$

The introduction of the rivaroxaban $10 \mathrm{mg}$ once daily regimen allows for a choice of doses for extended VTE treatment, providing flexibility for both physicians and patients. Although patient preference must always be a key consideration, the lower rivaroxaban dose may reassure patients and physicians that extended secondary prevention can be achieved with little risk of bleeding. Importantly, the updated European label for rivaroxaban allows for dose reescalation from rivaroxaban $10 \mathrm{mg}$ once daily to rivaroxaban $20 \mathrm{mg}$ once daily in the event that the patient's risk profile changes (e.g. because of VTE recurrence on the lower dose) ${ }^{29}$ this should provide further reassurance to patients and physicians.

With the introduction of the lower $10 \mathrm{mg}$ dose of rivaroxaban, the obvious question that arises is how should physicians select the best dose for each patient? Although the rivaroxaban $10 \mathrm{mg}$ once daily dose will be suitable for many patients, the higher $20 \mathrm{mg}$ once daily dose of rivaroxaban will continue to be more appropriate for patients at high risk of VTE recurrence or those who have experienced VTE recurrence on the lower dose. Similarly, patients with active cancer who elect to switch from LMWH to rivaroxaban would still be likely to benefit most from the rivaroxaban $20 \mathrm{mg}$ dose. On the other hand, the rivaroxaban $10 \mathrm{mg}$ dose may provide reassurance for patients who have experienced a prior bleeding event, those at a high risk of bleeding or those with lifestyle-based concerns around anticoagulation (e.g. patients who participate in contact sports).

It should be noted that the EINSTEIN CHOICE study was specifically designed to investigate how best to treat patients who are at equipoise regarding the need for continued anticoagulation ${ }^{12}$ and so its design is likely to have enriched the patient population with certain patient sub-groups and disfavoured the inclusion of others. Most patients with a major transient provoking factor for VTE (e.g. orthopaedic surgery) would not have been included in the trial because they would have no indication for extended therapy beyond 3 months. Similarly, patients with a major persistent provoking factor, 
such as anti-phospholipid syndrome or active cancer, have a clear indication for extended therapy, and many physicians would be unwilling to enrol such patients in a trial in which they would have a $33 \%$ chance of receiving ASA. Consequently, most of the patients with provoked VTE enrolled in EINSTEIN CHOICE had minor provoking factors, such as a body mass index greater than $30 \mathrm{~kg} / \mathrm{m}^{2}$ or a family history of VTE, which are often overlooked when an event is classified as provoked or unprovoked. It is, therefore, interesting to note that in the EINSTEIN CHOICE population, rivaroxaban not only reduced the risk of recurrence compared with ASA in patients with unprovoked VTE, but also in patients with VTE associated with minor provoking factors. ${ }^{12}$

A pre-specified analysis combined data from the EINSTEIN CHOICE and EINSTEIN EXT studies specifically to investigate the effect of minor persistent or minor transient provoking factors on the risk of VTE recurrence. ${ }^{30}$ In this analysis, recurrence rates in patients with VTE provoked by minor persistent or minor transient risk factors were not significantly lower than in those with unprovoked VTE, highlighting the importance of extended anticoagulation therapy in these patients. Perhaps most notably, patients with minor transient risk factors (e.g. a leg injury with impaired mobility) still had a cumulative annual risk of recurrence of $7.1 \%$ in those who stopped anticoagulation, 3.3\% in those who received ASA and $0.4 \%$ in those who received rivaroxaban. It will be interesting to see what impact these data will have on future trials and clinical practice in the coming years.

\section{Conclusion}

The results of the EINSTEIN CHOICE study build on previous extension studies to provide a new therapeutic option for patients with a continuing risk of VTE recurrence, including those with unprovoked VTE and those with VTE provoked by minor risk factors. Both rivaroxaban $20 \mathrm{mg}$ once daily and rivaroxaban $10 \mathrm{mg}$ once daily were found to be superior to ASA $100 \mathrm{mg}$ once daily without a significant increase in clinically relevant bleeding. Such results were consistent with those of the earlier AMPLIFY-EXT trial, which compared apixaban at doses of 5 or $2.5 \mathrm{mg}$ twice daily with placebo. Therefore, like apixaban, rivaroxaban, particularly the reduced dose, may provide reassurance for patients and physicians in cases where the decision to extend anticoagulation is less straightforward. Such reassurance is important because we have learned that VTE is often a chronic disease associated with a high rate of recurrence in patients if anticoagulation therapy is stopped.

\section{Conflict of Interest}

J.W. has received consultancy fees and honoraria from Bayer, Boehringer Ingelheim, Bristol-Myers Squibb, Daiichi Sankyo, Ionis, Janssen, Merck, Novartis, Pfizer and Portola. N.C. has received honoraria from Bayer.

\section{Acknowledgements}

The authors would like to acknowledge Victoria Burchell, who provided editorial support with funding from Bayer AG and Janssen Scientific Affairs, LLC.

\section{References}

1 Kearon C, Akl EA, Ornelas J, et al. Antithrombotic therapy for VTE disease: CHEST guideline and expert panel report. Chest 2016; 149(02):315-352

2 Kearon C, Ageno W, Cannegieter SC, Cosmi B, Geersing GJ, Kyrle PA; Subcommittees on Control of Anticoagulation, and Predictive and Diagnostic Variables in Thrombotic Disease. Categorization of patients as having provoked or unprovoked venous thromboembolism: guidance from the SSC of ISTH. J Thromb Haemost 2016; 14(07):1480-1483

3 Kuipers S, Schreijer AJ, Cannegieter SC, Büller HR, Rosendaal FR, Middeldorp S. Travel and venous thrombosis: a systematic review. J Intern Med 2007;262(06):615-634

4 Kelly J, Rudd A, Lewis R, Hunt BJ. Venous thromboembolism after acute stroke. Stroke 2001;32(01):262-267

5 Goldhaber SZ, Grodstein F, Stampfer MJ, et al. A prospective study of risk factors for pulmonary embolism in women. JAMA 1997; 277(08):642-645

6 Grainge MJ, West J, Card TR. Venous thromboembolism during active disease and remission in inflammatory bowel disease: a cohort study. Lancet 2010;375(9715):657-663

7 Nguyen GC, Bernstein CN, Bitton A, et al. Consensus statements on the risk, prevention, and treatment of venous thromboembolism in inflammatory bowel disease: Canadian Association of Gastroenterology. Gastroenterology 2014;146(03):835-848

8 Bauersachs RM, Lensing AWA, Prins MH, et al. Rivaroxaban versus enoxaparin/vitamin $\mathrm{K}$ antagonist therapy in patients with venous thromboembolism and renal impairment. Thromb J 2014; 12:25-32

9 Hutten BA, Prins MH. Duration of treatment with vitamin K antagonists in symptomatic venous thromboembolism. Cochrane Database Syst Rev 2006;(01):CD001367

10 Simes J, Becattini C, Agnelli G, et al; INSPIRE Study Investigators (International Collaboration of Aspirin Trials for Recurrent Venous Thromboembolism). Aspirin for the prevention of recurrent venous thromboembolism: the INSPIRE collaboration. Circulation 2014;130(13):1062-1071

11 Gómez-Outes A, Lecumberri R, Suárez-Gea ML, Terleira-Fernández AI, Monreal M, Vargas-Castrillón E. Case fatality rates of recurrent thromboembolism and bleeding in patients receiving direct oral anticoagulants for the initial and extended treatment of venous thromboembolism: a systematic review. J Cardiovasc Pharmacol Ther 2015;20(05):490-500

12 Weitz JI, Lensing AWA, Prins MH, et al; EINSTEIN CHOICE Investigators. Rivaroxaban or aspirin for extended treatment of venous thromboembolism. N Engl J Med 2017;376(13):1211-1222

13 Bauersachs R, Berkowitz SD, Brenner B, et al; EINSTEIN Investigators. Oral rivaroxaban for symptomatic venous thromboembolism. N Engl J Med 2010;363(26):2499-2510

14 Agnelli G, Buller HR, Cohen A, et al; AMPLIFY-EXT Investigators. Apixaban for extended treatment of venous thromboembolism. N Engl J Med 2013;368(08):699-708

15 Schulman S, Kearon C, Kakkar AK, et al; RE-MEDY Trial Investigators; RE-SONATE Trial Investigators. Extended use of dabigatran, warfarin, or placebo in venous thromboembolism. N Engl J Med 2013;368(08):709-718

16 Büller HR, Décousus H, Grosso MA, et al; Hokusai-VTE Investigators. Edoxaban versus warfarin for the treatment of symptomatic venous thromboembolism. N Engl J Med 2013;369(15):1406-1415

17 Raskob G, Ageno W, Cohen AT, et al. Extended duration of anticoagulation with edoxaban in patients with venous thromboembolism: a post-hoc analysis of the Hokusai-VTE study. Lancet Haematol 2016;3(05):e228-e236

18 Lee AY, Levine MN, Baker RI, et al; Randomized Comparison of Low-Molecular-Weight Heparin versus Oral Anticoagulant Therapy for the Prevention of Recurrent Venous Thromboembolism in Patients with Cancer (CLOT) Investigators. Low-molecular-weight heparin versus a coumarin for the prevention of recurrent venous 
thromboembolism in patients with cancer. N Engl J Med 2003;349 (02):146-153

19 Raskob GE, van Es N, Verhamme P, et al; Hokusai VTE Cancer Investigators. Edoxaban for the treatment of cancer-associated venous thromboembolism. N Engl J Med 2018;378(07):615-624

20 Young AM, Marshall A, Thirlwall J, et al. Comparison of an oral Factor Xa inhibitor with low molecular weight heparin in patients with cancer with venous thromboembolism: results of a randomized trial (SELECT-D). J Clin Oncol 2018;36(20):2017-2023

21 Khorana AA, Noble S, Lee AYY, et al. Role of direct oral anticoagulants in the treatment of cancer-associated venous thromboembolism: guidance from the SSC of the ISTH. J Thromb Haemost 2018;16(09):1891-1894

22 Becattini C, Agnelli G, Schenone A, et al; WARFASA Investigators. Aspirin for preventing the recurrence of venous thromboembolism. N Engl J Med 2012;366(21):1959-1967

23 Brighton TA, Eikelboom JW, Mann K, et al; ASPIRE Investigators. Low-dose aspirin for preventing recurrent venous thromboembolism. N Engl J Med 2012;367(21):1979-1987

24 Castellucci LA, Cameron C, Le Gal G, et al. Efficacy and safety outcomes of oral anticoagulants and antiplatelet drugs in the secondary prevention of venous thromboembolism: systematic review and network meta-analysis. BMJ 2013;347:f5133
25 Sobieraj DM, Coleman CI, Pasupuleti V, Deshpande A, Kaw R, Hernandez AV. Comparative efficacy and safety of anticoagulants and aspirin for extended treatment of venous thromboembolism: a network meta-analysis. Thromb Res 2015;135(05):888-896

26 Vasanthamohan L, Boonyawat K, Chai-Adisaksopha C, Crowther M. Reduced-dose direct oral anticoagulants in the extended treatment of venous thromboembolism: a systematic review and meta-analysis. J Thromb Haemost 2018;16(07):1288-1295

27 Prandoni P, Lensing AWA, Prins $\mathrm{MH}$, et al. Benefits and risks of extended treatment of venous thromboembolism with rivaroxaban or with aspirin. Thromb Res 2018;168:121-129

28 Kearon C, Ginsberg JS, Kovacs MJ, et al; Extended Low-Intensity Anticoagulation for Thrombo-Embolism Investigators. Comparison of low-intensity warfarin therapy with conventional-intensity warfarin therapy for long-term prevention of recurrent venous thromboembolism. N Engl J Med 2003;349(07):631-639

29 Bayer AG. Xarelto ${ }^{\circledR}$ (rivaroxaban) Summary of Product Characteristics. 2018. Available at: http://www.ema.europa.eu/docs/ en_GB/document_library/EPAR_-_Product_Information/human/ 000944/WC500057108.pdf. Accessed October 16, 2018

30 Prins MH, Lensing AWA, Prandoni P, et al. Risk of recurrent venous thromboembolism according to baseline risk factor profiles. Blood Adv 2018;2(07):788-796 